\title{
Modified Starches and Their Usages in Selected Food Products: A Review Study
}

\author{
K.A. Abbas (Corresponding author) \\ Department of Food Technology, Faculty of Food Science and Technology \\ Universiti Putra Malaysia, 43400 Serdang, Selangor, Malaysia \\ Tel: 603-8946-8534Ｅ-mail: ali_kassim@hotmail.com \\ Sahar K. Khalil \\ Faculty of Political Science, University of Al-nahrain, Baghdad, Iraq \\ Tel: 964-770-873-9943 E-mail: ali_kassim@hotmail.com \\ Anis Shobirin Meor Hussin \\ Department of Food Technology, Faculty of Food Science and Technology \\ Universiti Putra Malaysia, 43400 Serdang, Selangor, Malaysia \\ Tel: 603-8946-8352Ｅ-mail: shobirin@putra.upm.edu.my
}

\begin{abstract}
Modified starches have been developed for a very long time and it applications in food industry are really significant nowadays. This paper will elaborate more about the definition and classifications of modified starches by considering several modification techniques such as physical, chemical, and enzymatic treatment. Review on journal's papers of current decade has been done so as to observe the latest applications of modified starches in the food industry. In order to organize the findings, they have been divided into several sub-groups according to its functional applications, as fat replacer/fat mimetic, as texture improver, for high nutritional claim, for high shear and temperature stability, and for flavor oil encapsulation. Examples on its recent applications of specific foods products were also included. Hopefully this paper will assist anyone especially students who wants to get information about the latest applications of modified starch in the food industry.
\end{abstract}

Keywords: Treatments of starch, Applications, Food industry

\section{Introduction}

Starch or amylum is a polysaccharide carbohydrate consisting of a large number of glucose units joined together by glycosidic bonds. It comprises of amylose and amylopectin as it macromolecules. Starch is produced by all green plants as an energy store and is a important energy source for humans. It is found in potatoes, wheat, rice and other foods, and it varies in appearance, depending on its source. In the unmodified form, starches have limited use in the food industry. In general, native starches produce weak-bodied, cohesive, rubbery pastes when heated and undesirable gels when the pastes are cooled (Adzahan, 2002). That is why, the food manufacturers generally prefer starches with better behavioral characteristic than those provided by native starches. The properties of starches can be improved by various modifications.

Researches have developed methods to modify starch, which requires the usage of chemicals and enzymes. Modified starch is a food additive which is prepared by treating starch or starch granules, causing the starch to be partially degraded (Wikipedia, 2009). The purposes of this modification are to enhance its properties particularly in specific applications such as to improve the increase in water holding capacity, heat resistant behavior, reinforce its binding, minimized syneresis of starch and improved thickening (Adzahan, 2001; Miyazaki et al., 2006).

In order to select modified starch for a particular application, consideration about both the market and production are required. The market-related properties are product properties such as the structure, aesthetics, organoleptic consideration and shelf stability (Dies et al., 1997, Sajilata \& Singhal, 2004). While the production-related 
requirements are properties such as viscosity, resistant to shear, low $\mathrm{pH}$ and high temperature. Accordingly, varieties of modified starches are used in food industry. Table 1 lists some of the modified starches that can be prepared from different sources to meet the marketing-related requirements.

Today, modified food starch is a food additive and limits of its modification, use and labeling are clearly defined in the US Code of Federal Regulation (Sajilata \& Singhal, 2004). The European Directive on food additives allows the following food starches in food products (Wikipedia, 2009).

\begin{tabular}{|c|c|}
\hline E1401 & Acid-treated starch \\
\hline E1402 & Alkaline-treated starch \\
\hline E1403 & Bleached starch \\
\hline E1404 & Oxidized starch \\
\hline E1405 & Starches, enzyme-treated \\
\hline E1410 & Monostarch phosphate \\
\hline E1411 & Distarch glycerol \\
\hline E1412 & Distarch phosphate esterified with sodium trimetaphosphate \\
\hline E1413 & Phosphated distarch phosphate \\
\hline E1414 & Acetylated distarch phosphate \\
\hline E1420 & Starch acetate esterified with acetic anhydride \\
\hline E1421 & Starch acetate esterified with vinyl acetate \\
\hline E1422 & Acetylated distarch adipate \\
\hline E1423 & Acetylated distarch glycerol \\
\hline E1440 & Hydroxypropyl starch \\
\hline E1442 & Hydroxypropyl distarch phosphate \\
\hline E1443 & Hydroxypropyl distarch glycerol \\
\hline E1450 & Starch sodium octenyl succinate \\
\hline
\end{tabular}

Modified starches consist of starch with low to very low level of substituent group. Enzymatic modification of starch is hydrolysis of some part of starch into a low molecular weight of starch called maltodextrin, or dextrin using amylolytic enzymes (Miyazaki et al., 2006). They are widely used for food and pharmaceutical industries.

Physical modification involves pre-gelatinization, and heat-treatment of starch, etc (Miyazaki et al., 2006). Pre-gelatinized starches are pre-cooked starches that can be used as thickener in cold water (Wikipedia 2009). While the heat-treatment processes include heat-moisture and annealing treatments, both of which cause a physical modification of starch without any gelatinization, damage to granular integrity, or loss of birefringence.

Chemical modification is the mainstream of the modified starch in the last century. Many developments of chemical modification of starches have been introduced in food, pharmaceutical and textile industries. Table 2 shows the classification of modified starches available currently.

In order to investigate the uses of modified starches in selected food products, the findings has been divided in sub-groups according to their functional applications. Examples of the applications in selected food products will also be included as follows:

\subsection{As Fat Replacer/Fat Mimetic}

As a food component, fat contributes to the flavor, appearance, texture, and shelf life of food products (Mun et al., 2009). Consumers nowadays are really concerns about the adverse health effect of overconsumption of certain types of lipids, this has resulted in some development of reduced-fat food to solve the issue. It is difficult to imitate traditional product quality when preparing reduced-fat foods. A combination of nonfat ingredients with different functional roles can be used to replace the quality attributes lost when fat is removed (Mun et al., 2009).

Starch also can be modified by hydrolysis to form a fat replacer. Some well-known fat replacer from starch base is maltodextrin beside some other starch hydrolysis products. It is widely used for low-fat butter spread/margarine, low fat mayonnaise, low fat milk type products and low -fat ice cream (Sajilata \& Singhal, 2004). 


\subsubsection{Low-fat yogurt}

Some recent studies have been done in replacing fat with modified starch. Castilla et al., (2003), prepared three commercial fat replacers consisting of whey protein concentrate (WPC), microparticulated whey protein (MWP) and modified tapioca starch (MTS), along with the preparation of seven reduced-fat yogurts from reconstituted milk. They found that yogurts with WPC and blends of WPC and MWP possessed textural characteristics that resemble those of full-fat yogurt (FFY), whereas yogurt with MWP showed lower tension and firmness but higher cohesiveness. Yogurt with MTS showed higher firmness than FFY. Blends of carbohydrate-protein-based fat replacer resulted in yogurts that are less dense, firm and adhesive, but more cohesive than FFY.

Alting, et al., (2008), found a way to improve low-fat yogurt creaminess by using amylomaltase-treated starch (ATS) domain. They realized that ATS is a creaminess enhancer that is four times as effective as maltdextrin, which is currently used widely in set style yogurt as fat replacer. The creaminess perception of low-fat yoghurt $(1.5 \%)$ can be raised to that of full-fat yoghurt (5\%) with the presence of small amount of ATS. In the energy's consumption point of view, reduction in fat-related energy value could be achieved from 45 to $21.5 \mathrm{kcal} / 100 \mathrm{~g}$ product. The ATS domains are enclosed in or bound to the protein network which is the dominant microstructure of the yoghurt. The perceived creaminess resulted from melting of these ATS domains in the mouth is due to a combined effect of their physical melting and hydrolysis by amylase present in the saliva. In this way, the ATS domains resemble the microstructural behaviour of fat particles.

\subsubsection{Low-fat cheese}

Functionality of modified tapioca starch and lecithin as fat mimetic in Feta cheese was studied by Sipahioglu, Avarez \& Soleno-Lopez (2000). Cheeses were made without any fat mimetic, $1 \%$ modified tapioca starch, $0.2 \%$ lecithin, and a combination of $0.5 \%$ tapioca starch and $0.1 \%$ lecithin. Low-fat Feta cheeses $(9-16 \%$ fat) were prepared from bovine 1.6-2.2\% fat milk and were ripened for 45 days before analysis. Result shows that levels of fat and fat mimetic significantly affected moisture, protein, yield, and hardness of cheese. Reduced-fat cheeses with modified tapioca starch had the highest moisture (67.6\%) and lowest protein (13.5\%) content and their hardness was higher. SEM micrographs revealed that the size of protein aggregates increased as the fat content of the cheese decreased. The combination of modified tapioca starch and lecithin improved flavor, texture and overall acceptability of reduced-fat and low-fat Feta cheeses.

In addition, Koca and Metin (2003) studied the textural, melting and sensory properties of semi-hard Turkish traditional cheese, known as Kashar cheese which was produced by one of carbohydrate-based fat replacer namely, $5.0 \% \mathrm{w} / \mathrm{w}$ Raftiline ${ }^{\mathbb{R}} \mathrm{HP}$ with another two protein-base fat replacer $\left(1.0 \% \mathrm{w} / \mathrm{w}\right.$ Simplesse ${ }^{\circledR} \mathrm{D}-100$ and $1.0 \% \mathrm{w} / \mathrm{w}$ Dairy-Lo ${ }^{\mathrm{TM}}$ ). The result was being compared with the control samples of low-fat cheese without fat replacer and the full-fat cheese. The changes in cheese characteristics were examined during storage for 90 days. It was found that deterioration of hardness, springiness, gumminess and chewiness occurred due to the usage of fat replacers while cheese cohesiveness was increased. The use of carbohydrate-base fat replacer, Raftiline ${ }^{\mathbb{B}} \mathrm{HP}$ had slightly increased the cheese meltability. These results indicated that Simplesse ${ }^{\mathbb{B}} \mathrm{D}-100$ and Raftiline ${ }^{\mathbb{B}} \mathrm{HP}$ can improve the texture and sensory properties of low-fat fresh kashar cheese.

\subsubsection{Low-fat Mayonnaise}

In the production of low-fat mayonnaise, Mun et al., (2009), has used 4- $\alpha$-glucanotransferase (4aGTase) enzyme to modify the structural properties of rice starch in combination with xanthan gum. They concluded that the usage of $4 \alpha$ GTase-treated rice starch as a viable fat replacer in mayonnaise is feasible. This was supported by the finding that the $4 \alpha$ GTase-treated starch altered the rheological properties, stability, and microstructures of the fortified mayonnaises, but at the same time, these alterations were highly dependent upon the concentration of the oil and starch, and the presence of xanthan gum. They also suggested that the amount of $4 \alpha$ GTase-treated starch added to the mayonnaise samples is should be controlled with the combination of xanthan gum.

\subsection{As Texture Improvers}

Several studies have been carried out on the potential use of modified starches as texture improver in the food industry. It can provide crispness of crackers and biscuits, viscosity breakdown resistant for can foods, desired chewiness for certain foods and improvement in the quality of extruded products.

\subsubsection{Breadmaking}

Starch is a major components of breadmaking and plays an important role in texture and quality of the dough and bread. Modified starches were developed to decrease the undesirable properties of native starch, which will affect the properties of dough and quality of bread. Bread crumb prepared with phosphorylated cross-linked tapioca starch has a dry feel, whereas bread that was produced from flour substituted with native, 
hydroxypropylated and acetylated tapioca starches have a tacky texture (Miyazaki et al., 2005, 2006). The flour substituted with phosphorylated cross-linked tapioca starch showed lower peak viscosity and smaller breakdown, whereas that with native, hydroxypropylated and acetylated tapioca starches showed higher peak viscosity and large breakdown than wheat flour on the amylogram (Miyazaki et al., 2005).

Cross-linked cornstarches (CLCSs) and vital gluten had been used to substitute 5-15\% of wheat flour in bread making (Hung \& Morita, 2004). It was found that the substituted flours made stronger and more stable dough and produced bread of bigger loaf volume than did the control. Cross-linked cornstarch which was substituted for wheat flour improved the resistance and extensibility of dough against mixing and stretching. This, implied that an optimum amount of cross-linked starch can be substituted for wheat flour to improve the rheological properties of dough and quality of bread.

While Hung, Maeda \& Morita (2008) explained that recent advance of starch synthesis products of waxy wheat flour (WWF) and high-amylose wheat flour (HAWF) provide the unique starch functional properties required in breadmaking. They reported that the breadcrumbs from WWF were significantly softer than those of HAWF and non-waxy wheat flour during storage for up to 7 days, and remained softer after reheating. In contrast, the firmness of breadcrumbs from HAWF and non-waxy wheat flours after reheating increased distinctly as compared with the pre-heating breadcrumbs. He concluded that the soft, viscous and glutinous properties of breadcrumbs are attributed to waxy wheat flour.

\subsubsection{Crispy snack}

High amylose cornstarch is used in extruded and fried snack products to obtain crisp, evenly browned product. High amylose starches or slightly degraded waxy pregels can be used to give crunchy or crispy mouth feel because they can expand to tender structure when heated or dried. By incorporating the modified starch into the dough composition and by controlling the water absorption index of the starch-based materials, snacks can have a high degree of mouth melt, less waxiness, improved texture and increased crispiness (Sajilata \& Singhal, 2004).

Crispness is one of the most important quality aspects of battered food. Extensive research has been conducted to investigate the influence of batter ingredients on crispness development. The effect of various starch types (amylomaize, corn, waxymaize, pre-gelatinized tapioca) on quality attributes (texture, moisture content, oil content, color, coating pick up, cooking yield, volume and porosity) of deep-fat fried chicken nuggets were studied by Altunakar, Sahin \& Sumnu (2004). Chicken sample, taken from the breast portion were coated with batter formulations contained equal amounts of corn and wheat flour, $5.0 \%$ starch, $1.0 \%$ salt and $0.5 \%$ leavening agent. They found that, the addition of starch increased the crispness of the chicken nugget significantly at the last stage of frying. The samples crispness increased while the moisture content decreased with the increase in frying time. It was concluded that, pre-gelatinized tapioca starch was found to provide a product with the lowest oil content, the highest moisture content, coating pick up and volume.

In addition Sanz, Salvador \& Fiszman (2008), had done some tests of using resistant starch known as RS3 as part of non pre-frying batter for fried squid rings. After frying, the batter crust hardness and fragility were significantly increased with more intense brown-gold color. It was found that good batter performance during the manufacturing process without pre-drying depends on the successful development of thermogelling property of methyl cellulose (MC). They observed that RS3 did not interfere with the above process as well as did not affect the viscoelastic properties significantly. RS3 was suggested to be used in fried batter food prepared by a process without pre-frying.

\subsection{For High Nutritional Claim}

Resistant starch is claimed as a functional fiber since it allows high fiber nutritional claim and is well suited for food applications. It is starch that escapes digestion in the small intestine of healthy individuals (Wikipedia, 2009). Resistant starch is considered the third type of dietary fiber, as it can deliver some of the benefits of insoluble fiber and some of the benefits of soluble fiber. It has many advantages compared to traditional source of fiber due to it smaller crystallites which has low water-holding capacity, small particle size and bland flavor (Sajilata \& Singhal, 2004). Commercial resistant starch is a special high-amylose starch that has been modified by biochemical or physical processing to maximize its total dietary fiber content.

\subsubsection{Slow digestible cookies}

Saguilán et al. (2007) used resistant-starch rich powder (RSRP) prepared from autoclave-treated lintnerized banana starch in the making of slow digestible cookies. The chemical compositions, rate of starch digestion in vitro and the acceptance of RSRP-cookies made from different formulations were determined along with control 
cookie and white bread as reference. The best formulation that corresponds to a wheat flour:RRSP ratio of 15:85 was found to possess a lower glycemic index of 60.53 when compared with the control cookies (77.62) based on the prediction of hydrolysis index (HI). The hydrolysis curve is shown in Figure 1, while Table 3 explaining the hydrolysis index (HI) and predicted glycemic index (GI) of the products.

In conclusion, the usage of resistant starch-rich powder (RSRP) from banana starch can produced a bakery product with moderate available starch and slow release of carbohydrate features. The use of nutraceutical ingredients, such as RSRPs, may be useful in the development of new products for consumers sectors with reduced caloric and glycemic requirements.

\subsubsection{Resistant starch muffin}

Due to its health-benefit value, some research was done to replace the native starch with resistant starch. Baixauli et al. (2008A) studied the effect of replacing wheat flour with resistant starch (from native maize) on the quality of muffins. The volume, height and the number and area of gas cells in the muffins were decreased when resistant starch was used. The rheological properties of the raw batters such as: the mechanical spectra of batters at $25^{\circ} \mathrm{C}$, the evolution of the dynamic moduli $\left(G^{\prime}\right.$ - shear storage and $G^{\prime \prime}$ - loss modulli) with rising temperatures (from 25 to $85{ }^{\circ} \mathrm{C}$ ) and the mechanical spectra at $85{ }^{\circ} \mathrm{C}$ were also analyzed. The ratios of wheat to resistant starch studied were: $26 / 0 \%, 21 / 5 \%, 16 / 10 \%, 11 / 15 \%$ and $6 / 20 \%$. They noticed that the viscosity and the elastic properties of the muffin batter decreased as the flour was increased. Replacement by more than $10 \%$ resistant starch contributed to the decrease in the structural elements provided by wheat flour. Based on baking performance of the final baked products it was suggested that incorporation of extra ingredients that could raise the protein level into the formula, are likely to increase the elastic properties of the muffin batter during the heating process in the presence of high resistant starch.

In relation to the previous study, a survey has been done to observe acceptability of consumer towards resistant starch-muffin (Baixauli et al. 2008B). Three types of muffins comparisons of an experimental sample containing resistant starch (RS), and one plain muffin and one wholemeal muffins obtained from a local supermarket were evaluated. The respondent rated the "appearance", "texture", "flavour" and "overall acceptance" and the other health related questions With regards to muffins in different sessions. In the first session the consumers evaluated the muffin samples blindly. The three samples were presented in random order and were then rated. During the second session, one week later, the consumers were asked to evaluate the three samples again with awareness to its healthy benefits. Table 4 shows the mean liking scores of muffins attributes for both sessions.

Wholemeal muffins were rated the lowest when no information was given to consumers but the scores increased when consumers knew the fibre content of the product. This finding indicated that, the knowledge of certain nutritional facts affects the way that consumers perceive the attributes of the products. For RS muffins, however, the rise in scores was lower although the consumers has been told that it has same high-fibre content as wholemeal muffin. This could be due to the difference in the appearance between RS muffin and the ordinary wholemeal muffin.

\section{For Stability to High Shear and Temperature Conditions}

Hydroxypropyl starches are usually cross-linked to obtain desired texture and resistant to the high temperature, low $\mathrm{pH}$ and shear degradation that often encountered in food processing. Cross-linked starches will lose their clarity and water-holding capacity on prolonged low-temperature ageing. To tackle this issue, the starches will be acetylated with an acetyl containing of $0.5-2.5 \%$, the resistance to shear is retained and cold ageing stability is improved (Sajilata \& Singhal, 2005).

\subsection{High temperature gelling starches}

Gelatinization, pasting, and subsequent gel properties of starch are key functional properties that determine the various applications of starch in the food industry. Usually these properties are not optimal in native starch, and thus need to be modified by various techniques to suit the relevant end product. A study had been done by Gunaratne, Ranaweera \& Corke (2007) on thermal, pasting, and gelling properties of wheat and potato starches in the presence of sugars/modified starch (sucrose, glucose, glycerol, and hydroxypropyl $\beta$-cyclodextrin). Combination of starches with addition of sugars is commonly used in starch-based foods in order to optimize the process operation and provide certain textural modification beside its role as a sweetening agent. Gelatinization temperature and enthalpy of both starches were increased in the presence of sugar in the order of hydroxypropyl $\beta$-cyclodextrin $>$ sucrose $>$ glucose $>$ glycerol significantly above those of conventional gelling starches (about $70^{\circ} \mathrm{C}$ ). Sugars can stabilize the amorphous region by cross-linking starch chains such as polyol-starch chain interaction). Thus delaying the effect of starch gelatinization upon addition of sugars by decreasing the water 
activity, sugar-starch interaction and less plasticization effect of sugar than water. The higher the concentration of polyol the greater is the increase in gelatinization temperature.

\subsection{Salad mayonnaise}

The usage of modified starch as a water-soluble gelling agent to ensure stability of mayonnaise in high-shear emulsion especially for low-fat content of salad dressings and New Zealand-style mayonnaises were reported by Depree \& Savage (2001). In these products, much of the rheology of the product depends on the gelling agent rather than the nature of the emulsion. Scanning electron micrographs of such products show oil droplets either singly or as small aggregates dispersed throughout an open network of carbohydrate. It found that this product is far more stable than traditional high-fat mayonnaises. The modified starch used forms a strong enough gel to stabilize the product under high shear without creating an unpleasantly glutinous texture. Since the oil phase of the mayonnaise needs to be broken into very small droplets, whereas the gel phase is sensitive to shear stress, low fat dressings/mayonnaises are often prepared in two parts: oil in water emulsion resembling a traditional mayonnaise and an aqueous phase containing the gelling agent (modified starch). These two phases are then mixed together at low speed to produce the final product (Depree \& Savage, 2001).

\subsection{Starch-based dairy dessert}

Starch-based dairy desserts are widely consumed in Europe ("Natillas" in Spain, "Vanilla vla" in The Netherlands or "Crème dessert" in France). Basically, they are formulated with milk, thickeners (modified starch), sucrose, aroma and colorants. Generally, these products show time dependent and shear-thinning flow behavior, with viscoelastic properties typical of weak gels. Tárrega \& Costell (2006) examined on the effect of inulin addition on the rheological and sensory properties of fat-free dairy desserts containing different starch (waxy corn starch) concentrations $(2.5 \%, 3.25 \%$ and $4 \%)$ in comparison with that of full fat milk samples. According to Wikipedia (2009), inulins are a group of naturally occurring linear non-digestible polysaccharides of $\beta$-(2-1) linked fructose residues with a terminal glucose residue unit that is produced by many types of plants. The flow behavior of the dessert was observed by measuring shear stress value when shearing the samples with a linear increasing shear rate from 1 to $200 \mathrm{~s}^{-1}$ for a period of $60 \mathrm{~s}$ and in reverse sequence for the same time. All samples showed thixotropic and shear-thinning flow behavior. It was concluded that the addition of innulin in the product is dependent on the modified starch concentration to get the optimum rheological behavior. The use of hydroxypropylated starch from waxy corn will give the desirable texture with the present of carrageenan.

\section{For encapsulation of flavor oil}

In the presence of air, light, moisture and heat, generally most flavor components in food are highly volatile and chemically unstable. To overcome these problems, versatile techniques such as microencapsulation techniques has become popularly used. According to Wikipedia (2009), micro-encapsulation is a process in which tiny particles or droplets are surrounded by a coating to form small capsules that have many useful properties. In a relatively simplistic form, a microcapsule is a small sphere with a uniform wall around it. Various types of microcapsules, also referred to as wall materials, are prepared from natural polymers such as arabic gum, agar, wax, paraffin, casein, gelatin and of course modified starch.

\subsection{Volatile meat flavor encapsulation}

Jeon, Vasathan \& Song (2003), conducted a study on the suitability of using corn and barley starches as to be microcapsules to prevent flavor volatile of meat. Twelve samples were prepared from native and modified starches which consist of starches of regular corn (CR), regular barley (BR), waxy corn (CW), waxy barley (BW), succinylated regular corn (CRS), succinylated regular barley (BRS), succinylated waxy corn (CWS), succinylated waxy barley (BWS), octenyl succinylated regular corn (CROS), octenyl succinylated regular barley (BROS), octenyl succinylated waxy corn (CWOS) and octenyl succinylated waxy barley (BWOS). As for comparison, $\beta$-cyclodextrin $(\beta C D)$ which is a widely used wall material in the microencapsulation of essential oils or flavors was also put as a sample. Four different types of synthetic roasted chicken flavors, namely benzaldehyde, dimethyl trisulfide, 2-mercaptopropionic acid and benzothiazole, were selected in that test. Flavor-starch complexes were prepared by mixing flavors and gelatinized native or modified starches followed by lyophilization. The flavors were then extracted from the complex to determine their retention during the complex formation process with starches. Result as in Figure 2 shows that the CRS and BRS gave the best flavors retention as to compare with other starches and $\beta C D$.

The effects of storage on flavor retention were also investigated for duration of 4 weeks (Figure 3A, 3B and 3C). They found that starches which were modified by succinyl groups held the flavor better than the native starches, octenyl succinylated starches and $\beta C D$. 
Based on these findings it can be concluded that all starches were effective in encapsulating and retaining a model of volatile flavor mixture containing typical components of roasted chicken flavor. They also found that the starches tested retained flavors over a 4-week storage period better than $\beta$-cyclodextrin $(\beta C D)$, which is used commonly for encapsulation. Succinylated regular corn (CRS) and succinylated regular barley (BRS) showed the most promising results for flavor encapsulation.

\subsection{Spices oleoresins}

Although the spice oleoresins provide complete flavor profile than their respective essential oils, their sensitivity to light, heat and oxygen is a disadvantage. In order to encapsulate their flavor, Krishnan et al., (2005), found that a suitable mixture of arabic gum(GA), malt dextrin (MD) and a modified starch (MS) (octenyl succinylated waxy maize) can be used to encapsulate the oleoresin of one of the most famous spice in India which is cardamom (Elletaria cardamomum). The microencapsulation of cardamom oleoresin was done by spray drying using binary and ternary blends of arabic gum, maltodextrin, and modified starch as wall materials. Evaluations were done on stability of volatiles, entrapped 1, 8-cineole and entrapped $\alpha$-terpinyl acetate for 6 weeks and they found that the best efficient ratio of GA:MD:MS mixture was $(4 / 6,1 / 6,1 / 6)$. Other spices such as cumin also had been used as a sample to investigate the best ratio blend between gum arabic, maltodextrin and a modified starch $\left(\right.$ HiCap $\left.^{\circledR} 100\right)$ that can be used for encapsulation (Kanakdande et al., 2007). The microcapsules were also evaluated for the content and stability of volatiles, and total cuminaldehyde, $\gamma$-terpinene and $p$-cymene content for six weeks. They concluded that the same combination ratio of GA/MD/MS (4/6:1/6:1/6) blend proved to be efficient for the encapsulation of cumin oleoresin.

\section{Conclusions}

Demands of modified starches are increasing in parallel to the rapid development of food industry. From this review, it can be concluded that modified starches really offer tremendous number of functional benefits to variety of foods such as bakeries, snacks, beverages as well as nutritional foods. Although this paper divided the functional benefits of modified starches into 5 sub-groups which are; as fat replacer/fat mimetic, as texture improver, for high nutritional claim, for high shear and temperature stability, and for flavor/ oil encapsulation but yet there are many more benefits that need to be discovered. Other related benefits of modified starches are as follows: stabilizer, emulsifier, thickening agent, dusting agent, drying aids, binder, clouding agent, suspending agent and for freeze-thaw stability.

Future prospect of resistant starch should be explored in more details as the demands for healthy foods are increasing. Besides, the new development of genetically modified starches should be considered as a new interesting area to look into as it may replace the current method of starch modification by using enzyme, physical and chemical treatment.

\section{References}

Adzahan, N. M. (2002). Modification on wheat, sago and tapioca starches by irradiation and its effect on the physical properties of fish cracker (keropok). Food Technology. Selangor, University of Putra Malaysia. Master of Science: 222.

Alting, A. C., Velde, F. V. D., Kanning, M. W., Burgering, M., Mulleners, L., Sein, A., \& Buwalda, P. (2008). Improved creaminess of low-fat yoghurt: The impact of amylomaltase-treated starch domains. Food Hydrocolloids, 23(3): 980-987.

Altunakar, B., Sahin, S., \& Sumnu, G. (2004). Functionality of batters containing different starch types for deep-fat frying of chicken nuggets. European Food Research and Technology, 218(4): 318-322.

Baixauli, R., Sanz, T., Salvador, A., \& Fiszman, S. M. (2008A). Muffins with resistant starch: Baking performance in relation to the rheological properties of the batter. Journal of Cereal Science, 47(3): 502-509.

Baixauli, R., Salvador, A., Hough, G., \& Fiszman, S. M. (2008B). How information about fibre (traditional and resistant starch) influences consumer acceptance of muffins. Food Quality and Preference, 19(7): 628-635.

Castilla, O. S., Calleros, C. L., \& Carter, E. J. V. (2003). Microstructure and texture of yogurt as influenced by fat replacers. International Dairy Journal, 14(2): 151-159.

Depree, J. A., \& Savage, G. P. (2001). Physical and flavour stability of mayonnaise. Trends in Food Science \& Technology, 12(5-6): 157-163.

Gunaratne, A., Ranaweera, S., \& Corke, H. (2007). Thermal, pasting, and gelling properties of wheat and potato starches in the presence of sucrose, glucose, glycerol, and hydroxypropyl $\beta$-cyclodextrin. Carbohydrate Polymers, 70(1): 112-122. 
Hung, P. V., \& Morita, N. (2004). Dough properties and bread quality of flours supplemented with cross-linked cornstarches. Food Research International, 37(5): 461-467.

Hung, P. V., Maeda, T., \& Morita, N. (2008). Waxy and high-amylose wheat starches and flours-characteristics, functionality and application. Trends in Food Science \& Technology, 17(8): 448-456.

Jeon, Y. J., Vasanthan, T., Temelli, F., \& Song, B. K. (2003). The suitability of barley and corn starches in their native and chemically modified forms for volatile meat flavor encapsulation. Food Research International, 36(4): 349-355.

Kanakdande, D., Bhosale, R., \& Singhal, R. S. (2007). Stability of cumin oleoresin microencapsulated in different combination of gum arabic, maltodextrin and modified starch. Carbohydrate Polymers, 67(4): 536-541.

Koca, N., \& Metin, M. (2004). Textural, melting and sensory properties of low-fat fresh kashar cheeses produced by using fat replacers. International Dairy Journal, 14(4): 365-373.

Krishnan, S., Bhosale, R., \& Singha, K. (2005). Microencapsulation of cardamom oleoresin: Evaluation of blends of gum arabic, maltodextrin and a modified starch as wall materials. Carbohydrate Polymers, 61(1): 95-102.

Miyazaki, M. R., Maeda, T., \& Morita, N. (2005). Gelatinization properties and bread quality of flours substituted with hydroxypropylated, acetylated and phosphorylated cross-linked tapioca starches for wheat flour. Applied Glycoscience, 52(345-350).

Miyazaki, M. R., Hung, P. V., Maeda, T., \& Morita, N. (2006). Recent advances in application of modified starches for breadmaking. Trends in Food Science \& Technology, 17(2006): 591-599.

Mun, S., Kim, Y. L., Kang, C. G., Park, K. H., Shim, J. Y., \& Kim, Y. R. (2009). Development of reduced-fat mayonnaise using 4 $\alpha$ GTase-modified rice starch and xanthan gum. Biological Macromolecules, 44(5): $400-407$.

Saguilán, A. A., Ayerd, S. G. S., Torres, A. V., Tovar, J., Otero, T. A. E., \& Pérez, L. A. B. (2007). Slowly digestible cookies prepared from resistant starch-rich lintnerized banana starch. Journal of Food Composition and Analysis, 20(3-4): 175-181.

Sajilata, M. G., \& Singhal, R. S. (2004). Specialty starches for snack foods. Carbohydrate Polymers, 59(2005): 131-151.

Sanz, T., Salvador, A., \& Fiszman, S. M. (2008). Resistant starch (RS) in battered fried products: Functionality and high-fibre benefit. Food Hydrocolloids, 22(4): 543-549.

Sipahioglu, O., Alvarez, V. B. \& Solano-Lopez, C. (2000). Structure, physico-chemical and sensory properties of feta cheese made with tapioca starch and lecithin as fat mimetics. International Dairy Journal, 9(11): 783-789.

Tárrega, A., \& Costell, E. (2006). Effect of inulin addition on rheological and sensory properties of fat-free starch-based dairy desserts. International Dairy Journal, 16(9): 1104-1112.

Wikipedia. (2009). [Online] Available: http://www.wikipedia.com (August, 2009). 
Table 1. Types of specialty starches meeting some formulation needs (Sajilata \& Singhal, 2004)

\begin{tabular}{|c|c|c|c|c|c|}
\hline Marketing requirements & Regular maize & Waxy maize & High-amylose maize & Tapioca & Potato \\
\hline Gelled & Thin-boiling & & Thin-boiling & & \\
\hline Flowable & Stabilized & Cross-linked & & Cross-linked & Cross-linked \\
\hline Expanded & & Cross-linked & & Cross-linked & Cross-linked \\
\hline Rigid & & & Thin-boiling & & \\
\hline Rubbery & & & Thin-boiling & & \\
\hline Clarity & & Cross-linked & & Cross-linked & Cross-linked \\
\hline Opacity & Cross-linked & & $\begin{array}{l}\text { Cross-linked, } \\
\text { Thin-boiling }\end{array}$ & Thin-boiling & \\
\hline Pulpiness & $\begin{array}{l}\text { Pregelatinized and } \\
\text { cross-linked }\end{array}$ & & & $\begin{array}{l}\text { Pregelatinized and } \\
\text { cross-linked }\end{array}$ & \\
\hline Smoothness & & Cross-linked & & Cross-linked & Cross-linked \\
\hline Graininess & Cross-linked & & & Cross-linked & \\
\hline $\begin{array}{l}\text { High temperature } \\
\text { storage }\end{array}$ & Cross-linked & Cross-linked & & Cross-linked & Cross-linked \\
\hline $\begin{array}{l}\text { Low -temperature } \\
\text { stbrage }\end{array}$ & & $\begin{array}{l}\text { Stabilized, cross- } \\
\text { linked and stabilized }\end{array}$ & & $\begin{array}{l}\text { Stabilized, cross- } \\
\text { linked and stabilized }\end{array}$ & $\begin{array}{l}\text { Stabilized, cross- } \\
\text { linked and stabilized }\end{array}$ \\
\hline Low pH storage & Cross-linked & & & Cross-linked & Cross-linked \\
\hline
\end{tabular}

Table 2. Classification of modified starches (Miyazaki et al., 2006)

\begin{tabular}{|c|c|c|}
\hline Type of modification & & Products \\
\hline \multirow[t]{9}{*}{ Chemical modification } & Cross-linking & Distarch phosphate, etc. \\
\hline & Substitution & Starch esters: acetylated starch, starch phosphate, \\
\hline & & octenylsuccinate-treated starch, \\
\hline & & Starch ether: hydroxypropylated starch, \\
\hline & & carboxymethylated starch, cationized starch, etc \\
\hline & & Acid converted starch, oxidized starch, bleached \\
\hline & conversioun & starch \\
\hline & & Pyroconversion (dextrinization): dextrin, British gum, \\
\hline & & etc. \\
\hline \multirow[t]{3}{*}{ Physical modification } & Pregelatinization & Pregelatinized starch \\
\hline & Heat treatment & Heat-moisture treated starch, annealed starch \\
\hline & Radio treatment & Radio treated starch \\
\hline Enzymatic modification & & Maltodextrins, cyclodextrin, amylose, etc. \\
\hline
\end{tabular}


Table 3. Hydrolysis index (HI) and predicted glycemic index (pGI) of cookies with diverse resistant starch-rich powder levels (RSRP) (Saguilán et al. 2007)

\begin{tabular}{|l|l|l|}
\hline Sample & HI $^{*}$ & pGI $^{\#}$ \\
\hline Control cookie & $80.54 \pm 2.64^{\mathrm{a}}$ & 77.62 \\
\hline RSRP-cookie & $60.71 \pm 2.28^{\mathrm{b}}$ & 60.53 \\
\hline White bread reference & $100^{\mathrm{c}}$ & 94 \\
\hline
\end{tabular}

Table 4. Mean liking scores for plain muffin, wholemeal muffin and fibre-enriched muffin without and with label Information (Baixauli et al. 2008B)

\begin{tabular}{|c|c|c|c|c|c|c|}
\hline Attributes & \multicolumn{2}{|l|}{ Plain muffin } & \multicolumn{2}{l|}{ Wholemeal muffin } & \multicolumn{2}{l|}{ Fibre-enriched (RS) muffin } \\
\hline & $\begin{array}{c}\text { Without } \\
\text { information }\end{array}$ & $\begin{array}{c}\text { With } \\
\text { information }\end{array}$ & $\begin{array}{c}\text { Without } \\
\text { information }\end{array}$ & $\begin{array}{c}\text { With } \\
\text { information }\end{array}$ & $\begin{array}{c}\text { Without } \\
\text { information }\end{array}$ & $\begin{array}{c}\text { With } \\
\text { information }\end{array}$ \\
\hline Appearance & 7.2 & 7.3 & 5.5 & 5.8 & 5.9 & 6.2 \\
\hline Texture & 7.0 & 7.1 & 4.8 & 5.7 & 6.1 & 6.1 \\
\hline Flavour & 7.0 & 7.0 & 5.1 & 5.8 & 6.0 & 6.4 \\
\hline $\begin{array}{c}\text { Overall } \\
\text { acceptance }\end{array}$ & 7.0 & 7.0 & 5.0 & 5.7 & 6.0 & 6.2 \\
\hline Healthy & 5.8 & 6.0 & 6.0 & 6.5 & 5.4 & 6.1 \\
\hline Nutritious & 5.7 & 6.0 & 6.0 & 6.5 & 5.4 & 6.4 \\
\hline $\begin{array}{c}\text { Intention to } \\
\text { consume }\end{array}$ & 6.8 & 6.8 & 4.5 & 5.4 & 5.7 & 6.0 \\
\hline $\begin{array}{c}\text { Intention to } \\
\text { purchase }\end{array}$ & 6.4 & 6.4 & 4.0 & 5.0 & 5.3 & 5.5 \\
\hline
\end{tabular}

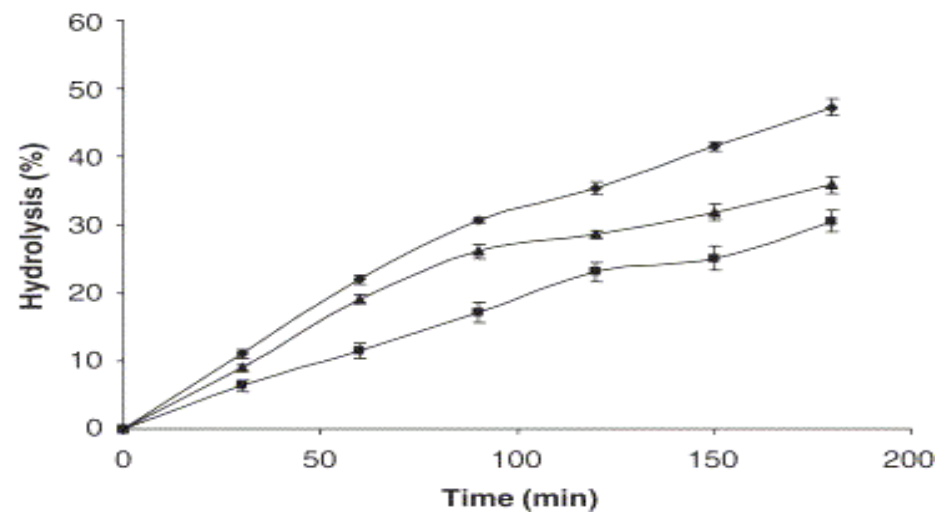

Figure 1. Average hydrolysis curves of: RSRP*-cookie $(\boldsymbol{\square})$, control cookie $(\boldsymbol{\Lambda})$, white bread used as reference ( ) (Saguilán et al. 2007) 


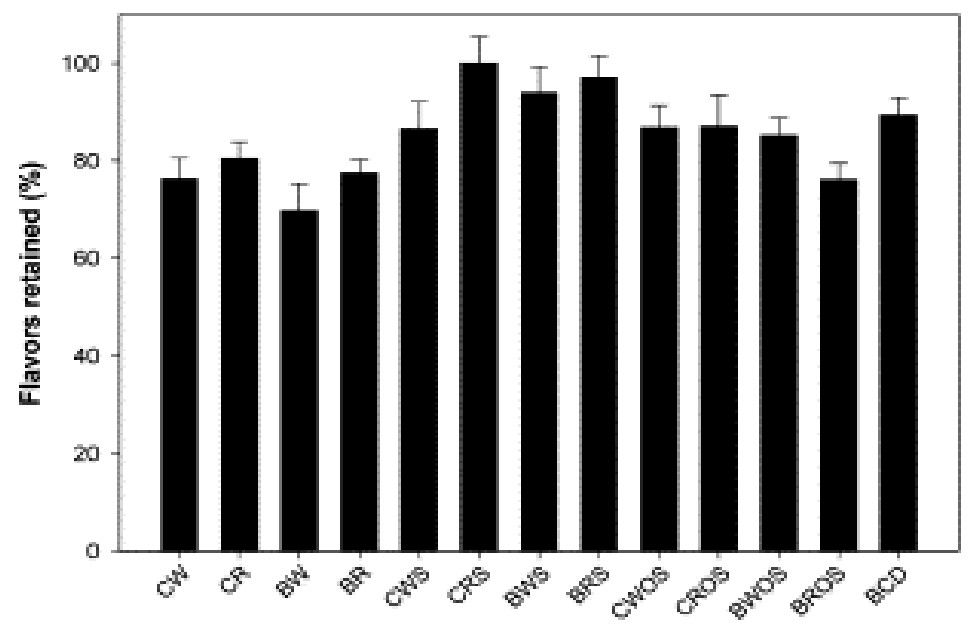

Figure 2. Total flavor retained by the wall materials (Jeon, Vasathan \& Song, 2003)

$3(\mathrm{~A})$

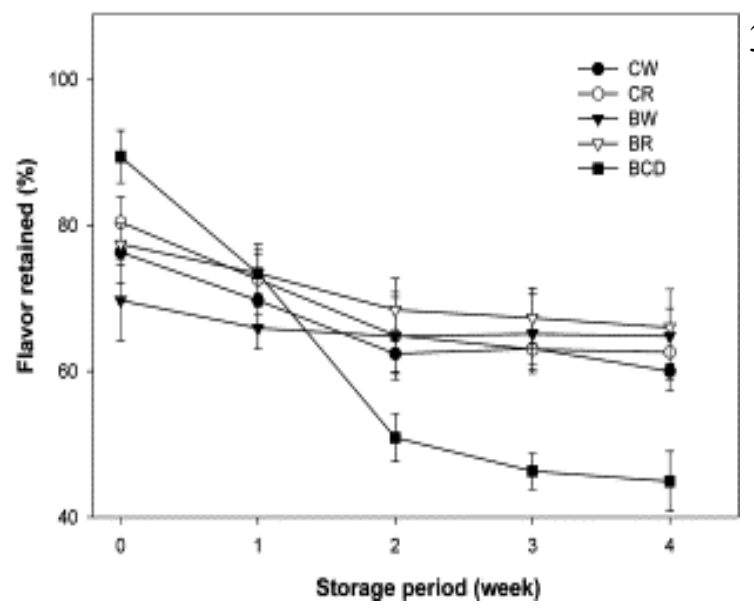

(B)

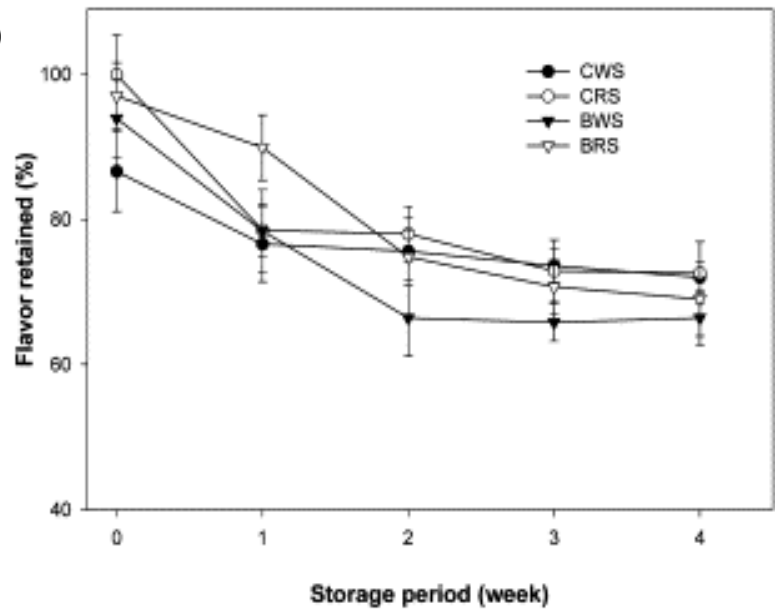

$3(\mathrm{C})$

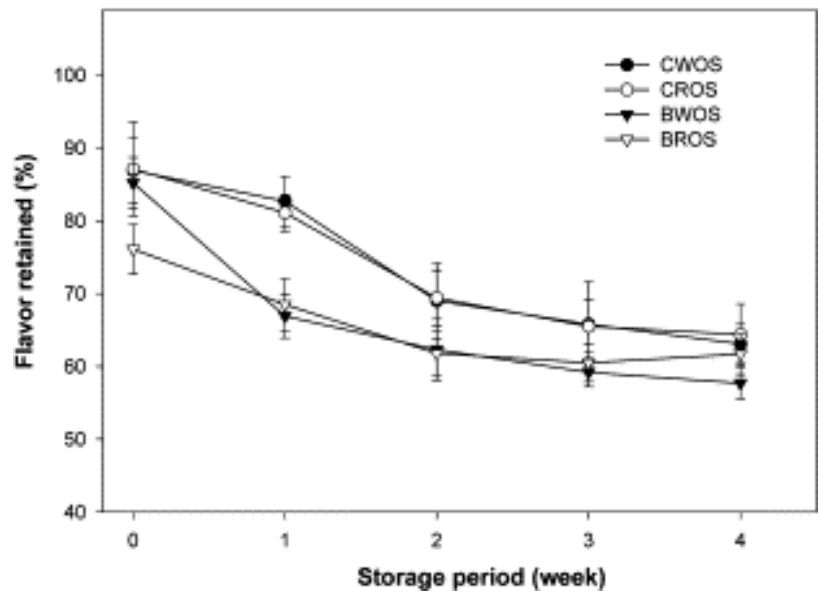

*Figure 3 (A). Flavor retention in native starches and $\beta C D$ during 4 weeks of storage

*Figure 3 (B). Flavor retention in the starches modified with succinyl groups during 4 weeks of storage

*Figure 3 (C). Flavor retention in the starches modified with octenyl succinyl groups during 4 weeks of storage *(Jeon, Vasathan \& Song, 2003) 